\title{
HOW TO BE SWEET? EXTRAFLORAL NECTAR ALLOCATION BY GOSSYPIUM HIRSUTUM FITS OPTIMAL DEFENSE THEORY PREDICTIONS
}

\author{
Felix L. WÄCKers ${ }^{1,3}$ AND Claire Bonifay ${ }^{2}$ \\ ${ }^{1}$ Netherlands Institute of Ecology, NIOO-CTE, Boterhoeksestr 48, 6666 GA Heteren, The Netherlands \\ ${ }^{2}$ Angewandte Entomologie, ETH-Z, Clausiusstr 25, CH-8006 Zürich, Switzerland
}

\begin{abstract}
Plants employ nectar for two distinct functions. Floral nectar has traditionally been viewed in the context of pollination. Extrafloral nectar on the other hand, can act as an indirect defense, allowing the plant to recruit predators and parasitoids. Whereas this makes for a clear-cut categorization, in reality the functions may not be so discrete. Extrafloral nectar may serve a role in pollination, while floral nectar can be utilized by predators and parasitoids and thus can contribute to plant defense. Here we use the optimal defense theory to generate predictions with respect to allocation patterns of defensive nectar. These predictions are then tested using novel data on the production patterns of bracteal and foliar nectar in cotton, Gossypium hirsutum.

Bracteal nectar production shows a distinct peak on the day of anthesis, followed by a prolonged secretion during fruit maturation. This suggests that bracteal nectaries function in pollination as well as defense. Constitutive nectar production at the bracteal nectaries exceeds foliar nectar secretion by a factor of between 80 and 110 . Whereas nectar production at foliar nectaries is induced following herbivore damage to leaves, bracteal nectar production is not induced in response to fruit damage and even decreases when the fruiting structure is subjected to herbivory. This shows that both an inducible and a constitutive variant of an indirect defense can occur within one plant species. This pattern of nectar allocation fits the optimal defense theory, which predicts high levels of constitutive defenses in valuable tissues such as fruits and induced defenses in less valuable tissues such as leaves. This result lends support to the interpretation that indirect defense has been a selective force in the evolution of bracteal nectaries. Although optimal defense theory has described direct defense allocation solely in terms of probability of attack and value of the plant structure, we argue that herbivore accessibility is an additional factor shaping the allocation of indirect defenses.
\end{abstract}

Key words: bracteal nectar; cotton; extrafloral nectar; foliar nectar; Gossypium hirsutum; herbivore refuge; indirect defense; multiple functions; nectar allocation; optimal defense theory; pollination.

\section{INTRODUCTION}

Parasitoids and predators can be important in regulating herbivore populations. The majority of these arthropods also need to consume sugar sources (e.g., nectar) to fuel their energetic needs (Porter 1989, Koptur 1992, Tobin 1994, Jervis et al. 1996). The availability of food supplements can drive the dynamics of predator-prey (Van Rijn et al. 2002) as well as parasitoidhost systems (Wäckers 2003).

By providing suitable food supplements, plants can recruit and retain predatory arthropods, which in turn may provide the plant with protection against herbivory. There is increasing ecological and evolutionary evidence for the defensive function of extrafloral nectar (Bentley 1977a, Koptur 1992, Heil et al. 2001). Plants may enhance the defensive function through strategic positioning of extrafloral nectaries and by adjusting

Manuscript received 16 June 2003; revised 3 September 2003; accepted 7 October 2003. Corresponding Editor (ad hoc): L. S. Adler. For reprints of this Special Feature, see footnote 1, p. 1477.

${ }^{3}$ E-mail: f.waeckers@nioo.knaw.nl nectar secretion patterns to the presence of herbivores (Bentley 1977a, Tilman 1978).

In cotton, extrafloral nectar production is determined by two genes that are independent of the inheritance of floral nectar (Rhyne 1965). It has been demonstrated that ants visiting foliar nectaries effectively protect wild cotton (Gossypium thurberi) from caterpillar damage (Rudgers 2003), ultimately enhancing seed production (Rudgers 2002). Ant recruitment by bracteal nectaries reduces fruit damage and fruit abortion rates in wild cotton, suggesting that bracteal, as well as foliar, extrafloral nectaries function in defense (den Held and Wäckers, unpublished data). The Hawaiian species Gossypium tomentosum lost its extrafloral nectaries (Fryxell 1979). This further corroborates the indirect defensive function of cotton extrafloral nectaries, given that ants until recently have been absent from the Hawaiian archipelago.

In addition to the defensive function of (extrafloral) nectaries, various alternative functions have been proposed, most of which are related to pollination. Bracteal nectar may act as an equivalent to floral nectar, 
attracting pollinators to the flower (Ford and Forde 1976, Sazima et al. 1993). Moreover, ants recruited to bracteal or calyx nectaries may protect flowers from nectar robbers (Inouye 1983), or may promote outcrossing by reducing the time pollinators spend visiting flowers of a particular plant (Altshuler 1999). Ants can also be costly rather than beneficial, as they may rob floral rewards and/or castrate flowers, generally without contributing to pollination (Beattie 1985). Extrafloral nectar may serve to prevent these problems by distracting ants away from delicate flowers (Trelease 1879, Wagner and Kay 2002).

Here we investigate whether the temporal and spatial pattern of extrafloral nectar production is consistent with its putative function in indirect defense. We use the optimal defense theory (ODT) to generate predictions with respect to levels of extrafloral nectar production and the inducibility of nectar secretion. Subsequently, we test these predictions using novel data on bracteal and foliar nectar production in Gossypium hirsutum L. (cotton). The fact that this species features extrafloral nectar on both vegetative and reproductive tissues makes it particularly suited to address optimality of indirect defense.

The ODT assumes that defensive traits are produced and allocated in a pattern that optimizes the trade-off between costs and defensive benefits (McKey 1974, 1979, Rhoades 1979, Zangerl and Rutledge 1996). Plants are predicted to allocate defenses in direct proportion to the value of the plant tissue and the likelihood that a tissue will be attacked (Zangerl and Bazzaz 1992, Zangerl and Rutledge 1996).

Vegetative tissues are usually less valuable and relatively easy to replace (McKey 1979, Zangerl and Bazzaz 1992), whereas flowers and particularly fruits represent a high value due to their direct link to the plant's reproductive success. Moreover, reproductive structures are often more likely to be attacked (Zangerl and Bazzaz 1992) and even low levels of damage may result in fruits being aborted (Karban and Baldwin 1997). Based on these differences, the ODT makes two predictions with respect to defense allocation between vegetative and reproductive structures:

1) Reproductive structures should receive a higher proportion of the overall defensive investment.

2) Foliar defenses should be inducible, whereas reproductive tissues are predicted to have high levels of constitutive (i.e., non-inducible) defense (Zangerl and Bazzaz 1992).

Both predictions have previously been corroborated for direct defenses. Overall, reproductive structures typically feature high levels of constitutive resistance that are rarely inducible (Zangerl and Bazzaz 1992, Zangerl and Rutledge 1996, Karban and Baldwin 1997), whereas vegetative structures often show low constitutive levels that are frequently inducible (Zan- gerl and Rutledge 1996, Karban and Baldwin 1997, Agrawal and Karban 1999).

Studies addressing induction of extrafloral nectar secretion have yielded mixed results. Increased secretion of extrafloral nectar in response to herbivory has been demonstrated in several plant species (Koptur 1989, Agrawal and Rutter 1998, Heil et al. 2001, Wäckers et al. 2001, Ness 2003). However, other plants do not increase nectar production in response to damage (Koptur 1989, Engel et al. 2001). A unifying theory to explain these differences has not yet been proposed. Here we use a single plant species and a standard induction procedure to establish patterns of foliar and bracteal nectar production and to test whether these patterns fit ODT predictions.

\section{Methods}

Cotton plants (Gossypium hirsutum (L.) (Malvaceae)) were grown individually under standardized conditions (14L:10D at light intensity of 510 $\mu \mathrm{mol} \cdot \mathrm{m}^{-2} \cdot \mathrm{s}^{-1}$; temperature $=23^{\circ} \mathrm{C}($ day $) / 15^{\circ} \mathrm{C}($ night $)$; relative humidity $80 \%$ ). Damage-free plants were used in the experiments as soon as the first flower bud was $2 \mathrm{~cm}$ long (approximately three months after germination). G. hirsutum features single foliar nectaries located on the leaf midrib, as well as three bracteal nectaries located at the base of each of the three bracts per flower.

\section{Bracteal nectar: pattern of constitutive nectar production and response to herbivory}

To establish the pattern of constitutive nectar production, we collected nectar from the first reproductive structure of 20 plants. When additional buds were formed, these were not included in our measurements. Daily bracteal nectar collection started an estimated two weeks before flowering and was continued for four weeks after anthesis. Nectar production was expressed as total per reproductive structure (summed over the three bracteal nectaries) per day. Collections were done at noon using absorbent soft tissue paper. A piece of tissue $\left( \pm 1 \mathrm{~cm}^{2}\right)$ was pre-weighed on a microbalance (Mettler MT5 $\pm 2 \mu \mathrm{g}$; Mettler-Toledo GmbH, Schwerzenbach, Switzerland). Using tweezers, we gently pressed the paper against the nectaries, thereby absorbing any nectar present without damaging the fragile nectar glands. By re-weighing the tissue paper at the time of collection, we could determine the nectar production (fresh mass).

For nectar sugar analysis, we collected samples of 1 $\mu \mathrm{L}$ of bracteal nectar from a separate set of five plants using $5-\mu \mathrm{L}$ micropipettes with $1-\mu \mathrm{L}$ divisions. These collections were done on the day of flowering (day 0 ), as well as on days 7,14 , and 21 . On the remaining days, nectar was removed as just described. Sugar composition was assessed by means of high-performance liquid chromatography, HPLC (Wäckers and Steppuhn 2003). The overall sugar content was calculated as the

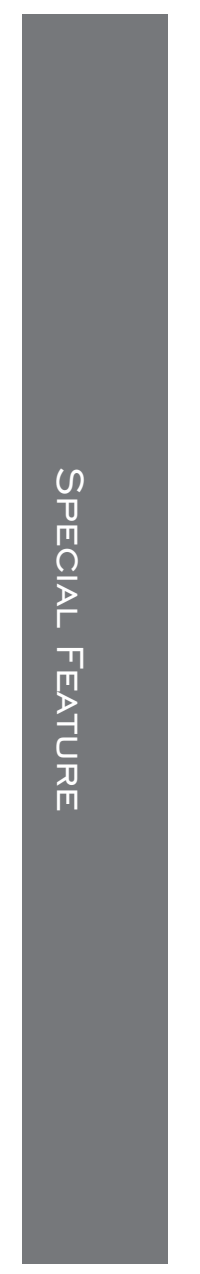




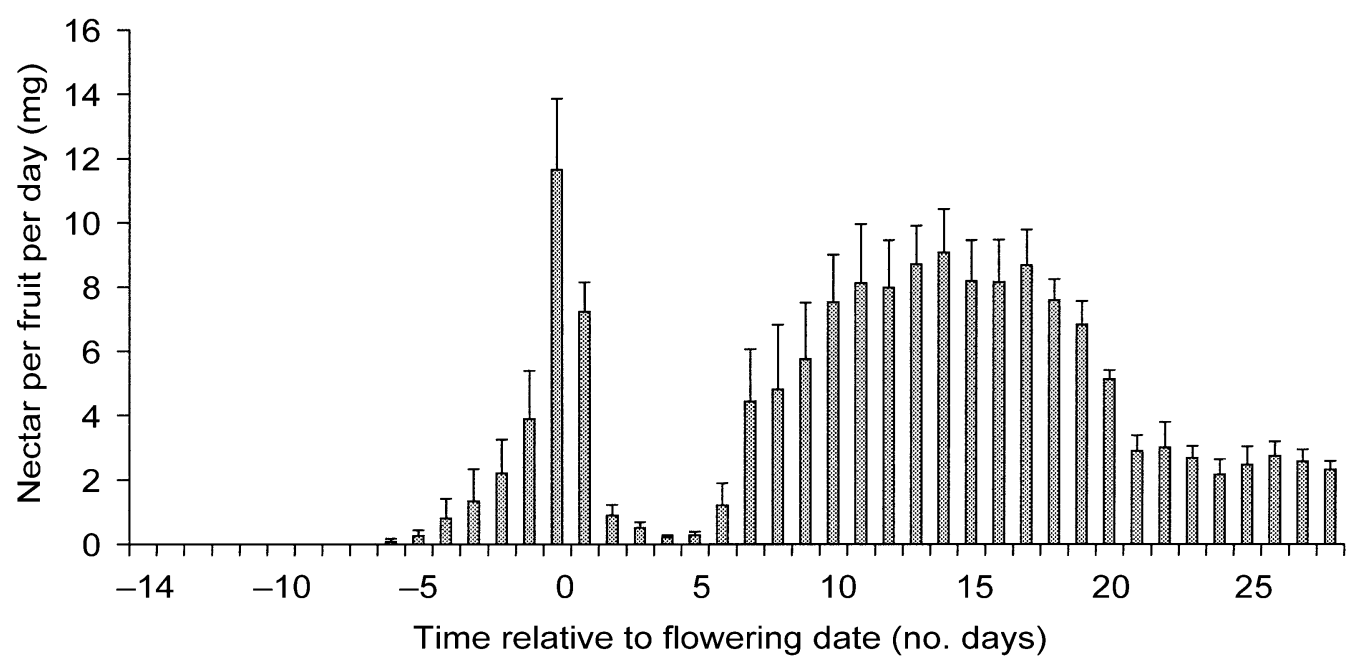

FIG. 1. Mean (+ $1 \mathrm{SD})$ daily bracteal nectar production by Gossypium hirsutum over the time of flower development and fruit maturation $(N=20$ plants). Values represent nectar produced per reproductive structure, summed over the three bracteal nectaries. Day 0 is the day of anthesis.

sum of the concentrations of the individual sugars. Based on the sugar concentration, mass data can be converted to volume ( $1 \mathrm{mg}$ of nectar at a concentration of $65 \%$ corresponds to a volume of $0.76 \mu \mathrm{L})$.

To test whether nectar production can be induced by herbivory, 7-d-old cotton fruits were exposed to thirdinstar cotton leafworms, Spodoptera littoralis (Novartis, Basel, Switzerland) or to a control treatment ( $n=$ 20 plants/treatment). This species was selected because it feeds on cotton leaves, as well as on buds and fruits (Kranz et al. 1977). Moreover, it had been used in previous cotton induction experiments (Wäckers et al. 2001, Bezemer et al. 2003).

To expose plants to herbivory, an individual larva was placed within a paper cone that was subsequently fitted tightly over the top of a young fruit. Control plants received an empty paper cone. Cones and herbivores were removed after 24 hours, by which time the herbivore had typically chewed a $0.5-1 \mathrm{~cm}^{2}$ hole in the fruit. Nectar was collected according to the method just described. Daily nectar collections started three days before treatment and continued for 10 days after treatment. Fruits that aborted during this period were discarded. Because data were normally distributed (Kolmogorov-Smirnov), treatments were compared using repeated-measures ANOVA.

\section{Foliar nectar production in response to herbivory}

Foliar nectar was collected daily for 10 days, using a separate batch of 20 plants. Foliar nectar was collected cumulatively over all leaves (7-9) per plant using the method described previously. Following nectar collection on day 3 , half of the plants received a clip cage with one $S$. littoralis larvae. The other half received an empty clip cage (control). After 24 hours, larvae had consumed the leaf area within the clip cages, at which time cages were removed. Treatments were compared using repeated-measures ANOVA.

\section{RESUlts}

\section{Bracteal nectar: pattern of constitutive nectar production and response to herbivory}

Secretion of bracteal nectar started 5-6 days before flowering and continued throughout the course of the experiment (Fig. 1). Nectar production showed a distinct peak on the day of flowering, when an average of $11.7 \mathrm{mg}$ of nectar was secreted per flower. After flowering, daily nectar production fell sharply to $0.23 \mathrm{mg} /$ flower four days after pollination. The subsequent two weeks of fruit growth showed a renewed increase in nectar secretion. From day 21 onward, nectar production levels stabilized (Fig. 1).

The nectar composition varied with development of the reproductive structure. Nectar secreted on the day of flowering contained $54 \pm 3 \%$ (mean $\pm 1 \mathrm{sD}$; mass/ mass) sugar (7\% sucrose, $26 \%$ glucose, $21 \%$ fructose). Nectar produced during fruit maturation had overall sugar concentrations of $74 \pm 5 \%, 65 \pm 3 \%$, and $64 \pm$ $5 \%$ on days 7,14 , and 21 , respectively. This nectar, too, was dominated by glucose and fructose.

During the three days before treatment, plants in the assigned control and herbivory groups did not differ in their nectar production (repeated-measures ANOVA, $\left.F_{1,38}=2.11, P=0.15\right)$. Herbivory did not result in a further increase in bracteal nectar production (Fig. 2). From day 15 onward, herbivore-damaged fruits actually produced less than half the nectar produced by their undamaged counterparts. Calculated over the period following herbivory, this resulted in a significant negative effect of herbivory on nectar secretion (repeated-measures ANOVA, $F_{1,38}=5.75, P=0.021$ ). Herbivory did not affect the sugar concentration of 


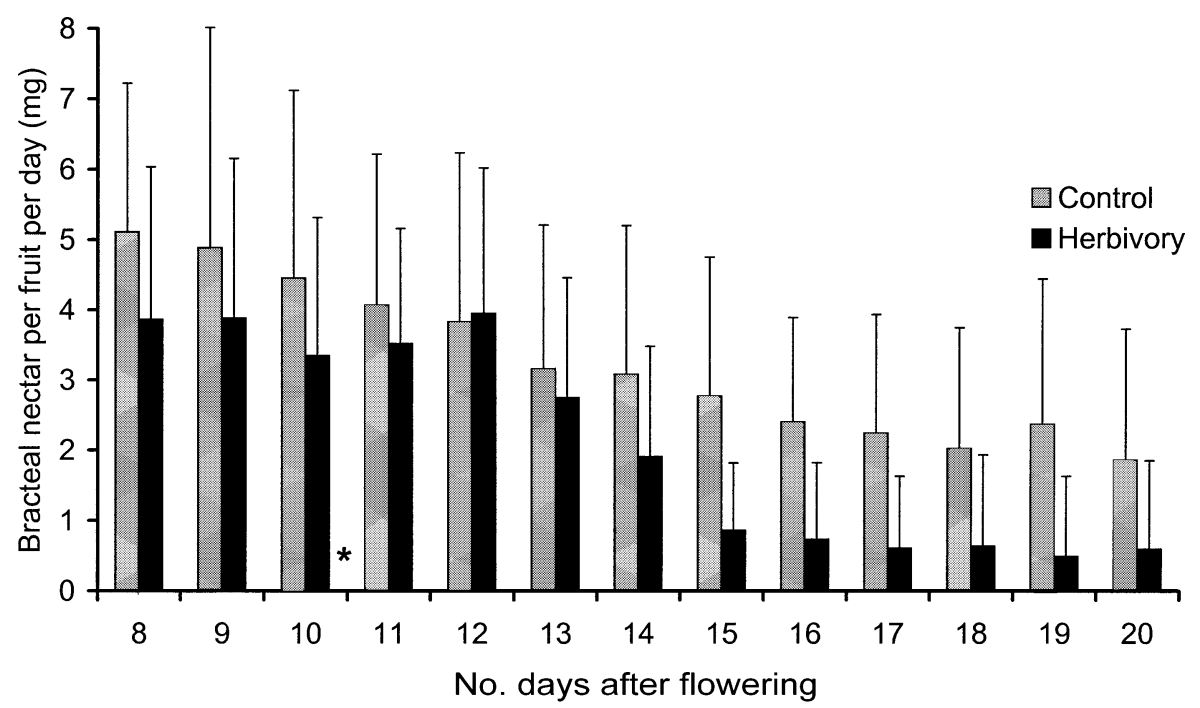

FIG. 2. The effect of Spodoptera littoralis herbivory on bracteal nectar production (mean +1 SD) in G. hirsutum. Developing fruits were exposed to 24 hours of herbivory at day 10 following anthesis (treatment is indicated by the star). Control plants remained undamaged. We tested 20 plants per treatment.

bracteal nectar (repeated-measures ANOVA, $P=$ $0.63)$.

\section{Foliar nectar production}

Foliar nectar production by undamaged plants ranged between 79 and $204 \mu \mathrm{g}$ per plant per day (Fig. 3), an order of magnitude less than the nectar produced by bracteal nectaries. During the three days before treatment, plants assigned to control and herbivory groups did not differ in their nectar production (repeated-measures ANOVA, $F_{1,18}=0.02, P=0.89$ ). Following herbivory on day 3 , foliar nectar production increased sig- nificantly in damaged plants (repeated-measures ANOVA, $F_{1,18}=21.6, P=0.0002$ ). By day 7 , foliar nectar production had returned to control levels.

\section{Discussion}

The pattern of extrafloral nectar production in Gossypium hirsutum fits both ODT predictions. First, bracteal nectar secretion greatly exceeds foliar nectar production. Second, whereas foliar nectar production is clearly inducible, bracteal nectar production is not raised following fruit herbivory. Instead, herbivory eventually results in a decline of bracteal nectar pro-

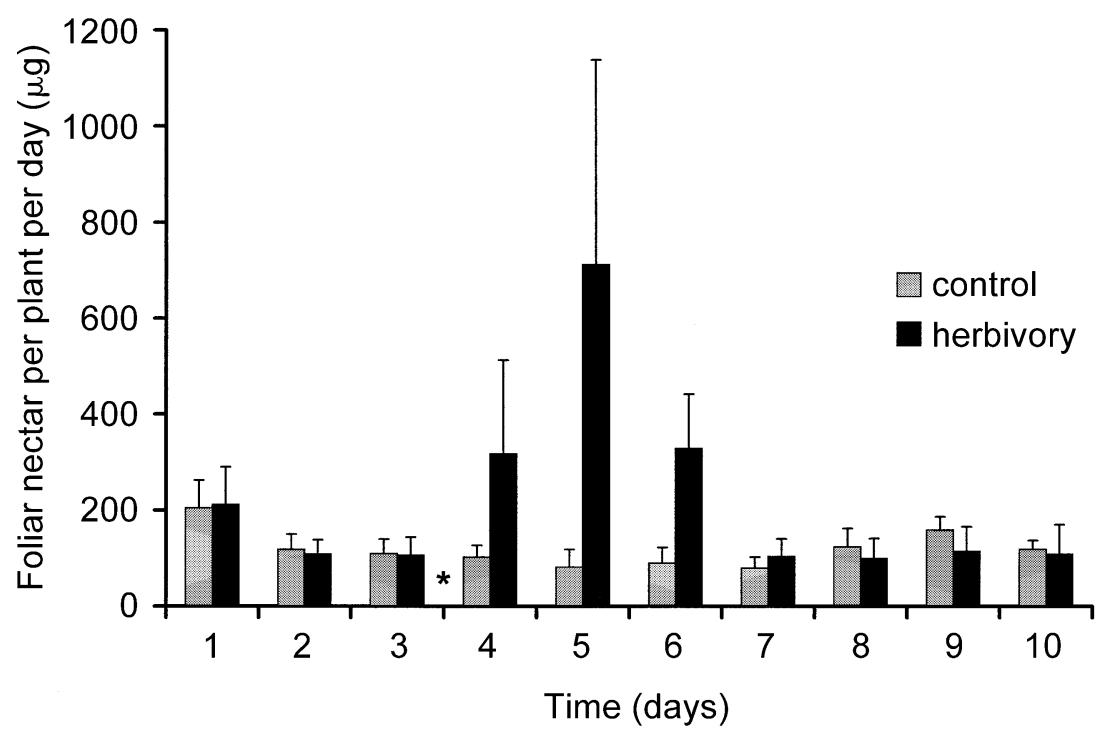

FIG. 3. Daily foliar nectar production (mean $+1 \mathrm{SD}$ ) by G. hirsutum plants in response to 24-h exposure to $S$. littoralis feeding. Damage was inflicted following the third nectar collection (day 3, indicated by the star). Control plants remained undamaged. Nectar is cumulated over all available leaves. Values are averaged over 20 plants tested per treatment. 
duction coinciding with a reduction in fruit growth and early fruit maturation. The high level of constitutive bracteal nectar production is likely to provide "prophylactic" protection for the valuable and vulnerable fruits. The less valuable leaves are protected in a "curative" manner with low constitutive production and a sharp increase in nectar secretion following herbivory. This demonstrates that an inducible and a non-inducible variant of an indirect defense can occur together within one plant species. The agreement between ODT predictions and actual allocation patterns lends support to the defensive function of cotton extrafloral nectaries.

Alternatively, the lack of induction of cotton bracteal nectar could be attributed to experimental conditions that prevented induction (Koptur 1992, Baldwin 1994). This seems unlikely in our experiments, given that foliar nectar was readily induced in plants of the same phenological stage, exposed to the same herbivore, and kept under identical conditions. Alternatively, the level of herbivory could have been insufficient to elicit nectar induction. However, fruits exposed to increased levels of herbivory showed a sharp decrease in nectar secretion followed by fruit abscission.

Parallel to the functional interpretation of defense allocation patterns, it is also important to consider the mechanisms underlying these patterns. Analogous to the substrate-enzyme imbalance theory, which regards defensive compounds as waste products (Haslam 1986), extrafloral nectaries have been interpreted as sugar valves through which plants excrete surplus sugars (Rhyne 1965, Bory and Clair Maczulajtys 1986). This theory is in accordance with the fact that the activity of extrafloral nectaries often correlates with the local requirements for nutrients and assimilates (sink strength) (Bentley 1977b). The observation that herbivory can induce sink strength in young leaves, as evidenced by increased transport of ${ }^{13} \mathrm{C}$-labeled carbon, also fits this model (Arnold and Schultz 2002). Unfortunately, less information is available to relate sink strength in fruits with herbivory. Within-plant variation in induction patterns may also be based on the vascular architecture of the plant (Orians et al. 2000). Signals involved in defense induction are often transported from sources to sinks. Because the cotton fruit constitutes a particularly strong sink (Wullschleger and Oosterhuis 1990), it is possible that the plumbing of the cotton reproductive structure prevents signals from reaching the bracts.

Although it will be intriguing to elucidate the mechanisms underlying the variation in nectar production, it should be emphasized that mechanistic explanations do not preclude a functional interpretation of nectary placement and nectar production patterns in terms of indirect defense. Selection is expected to favor the development of extrafloral nectaries at those locations where resultant nectar production yields the most effective protection (Bentley 1977a).
The ODT has been developed to study and understand the allocation of direct defenses. Direct defense allocation depends on probability of attack and value of the plant structure (Zangerl and Rutledge 1996). In predator-mediated indirect defense, on the other hand, the accessibility of the feeding herbivore is likely to be an additional factor shaping the pattern of defense allocation. Induced nectar production can be effective as an indirect defense against most leaf feeders, because they are usually fully exposed to their enemies. Voluminous cotton flower buds and fruits, on the other hand, provide endophytic herbivores with a refuge where they are inaccessible to most predators. Induced nectar production would be ineffective in this instance as it recruits predators at a time when the herbivore has already entered the fruit. Endophytic herbivores may actually benefit from induced ant recruitment, if patrolling ants chase away their antagonists (Koptur and Lawton 1988). Constitutive nectar production, on the other hand, can be effective against endophytic herbivores. Patrolling ants can both prevent adult herbivores from ovipositing and attack larvae before they enter the fruit. Thus, constitutive production of bracteal nectar may be explained by the mode of herbivory, as well as by the high value of reproductive structures.

The bracteal nectar production in G. hirsutum can be divided into two distinct periods. The first period is centered around flowering and shows a distinct peak on the day of actual anthesis. The second (prolonged) period starts six days after pollination. Although nectar produced during this second period probably has a strictly defensive function, the marked peak in nectar secretion during flowering and the reduced sugar concentration indicate that bracteal nectaries may serve an additional function in pollination either by attraction of pollinators or distraction of ants (Wagner and Kay 2002). In the field, cotton bracteal nectaries are indeed intensively visited by hymenopteran pollinators, which often show a distinct preference for bracteal over floral nectaries. Once drawn in by the bracteal nectar, some of these pollinators may switch to the floral rewards (McGregor 1976).

The temporal pattern of extrafloral nectar production at reproductive structures had previously been studied in the tropical shrub Bixa orellana (Bentley 1977b). Interestingly, and in sharp contrast with our findings, pedicellar nectar production in $B$. orellana peaks during bud maturation and shows a fivefold drop during flowering. This drop may reflect the relatively low vulnerability of the open flower to herbivores (Bentley $1977 b$ ), or may serve to avoid ant-pollinator conflicts (Raine et al. 2002). This example shows that nectar production patterns may differ markedly between species, probably reflecting species-specific functions.

In addition to the marked variation in the quantity of bracteal nectar production over the course of flower and fruit development, we also recorded some degree of variation in nectar concentration. The reduced sugar 
content of bracteal nectar during flowering may facilitate pollinator recruitment, because many pollinators have been adapted to deal with relatively dilute floral nectars (Baker and Baker 1982, Martínez del Rio et al. 2001). The increase in bracteal nectar concentration during fruit maturation may enhance the defensive function of extrafloral nectar. Highly concentrated nectar reduces intake by visiting ants and increases the duration of ant visits (Josens et al. 1998). Moreover, it discourages a range of unintended visitors, including herbivores, from exploiting the nectar (Wäckers et al. 2001).

The combination of a pollination and defensive function of $G$. hirsutum bracteal nectaries would be analogous to the dual function proposed for postfloral nectaries, i.e., floral nectaries that extend nectar secretion for several days or weeks after pollination (Daumann 1932). Following pollination, postfloral nectaries often attract ants that can provide protection against seed predators (Keeler 1981). Here as well, the switch between pollination reward and defensive function may be facilitated by changes in nectar composition (Gracie 1991).

Although the relative contribution of pollinators and predators to the evolution of nectary traits probably varies between plant species, examples given in this paper show that the evolution and functioning of nectaries can only be fully understood if the selective forces of pollination and indirect defense are both considered.

\section{ACKNOWLEDGMENTS}

We thank N. van Dam, J. Harvey, A. Michel, and three anonymous reviewers for helpful comments.

\section{LiTERATURE CITED}

Agrawal, A. A., and R. Karban. 1999. Why induced defenses may be favored over constitutive strategies in plants. Pages 45-61 in R. Tollrian and C. D. Harvell, editors. The ecology and evolution of inducible defenses. Princeton University Press, Princeton, New Jersey, USA.

Agrawal, A. A., and M. T. Rutter. 1998. Dynamic anti-herbivore defense in ant-plants: the role of induced responses. Oikos 83:227-236.

Altshuler, D. L. 1999. Novel interactions of non-pollinating ants with pollinators and fruit consumers in a tropical forest. Oecologia 119:600-606.

Arnold, T. M., and J. C. Schultz. 2002. Induced sink strength as a prerequisite for induced tannin biosynthesis in developing leaves of Populus. Oecologia 130:585-593.

Baker, H. G., and I. Baker. 1982. Chemical constituents of nectar in relation to pollination mechanisms and phylogeny. Pages 131-171 in M. H. Nitecki, editor. Biochemical aspects of evolutionary biology. University of Chicago Press, Chicago, Illinois, USA.

Baldwin, I. T. 1994. Chemical changes rapidly induced by folivory. Pages 1-23 in E. A. Bernays, editor. Insect-plant interactions. Volume V. CRC Press, Boca Rotan, Florida, USA.

Beattie, A. J. 1985. The evolutionary ecology of ant-plant mutualisms. Cambridge University Press, Cambridge, UK.

Bentley, B. L. 1977a. Extrafloral nectaries and protection by pugnacious bodyguards. Annual Review of Ecology and Systematics 8:407-427.
Bentley, B. L. 1977b. The protective function of ants visiting the extrafloral nectaries of Bixa orellana (Bixaceae). Journal of Ecology 65:27-38.

Bezemer, T. M., R. Wagenaar, N. M. van Dam, and F. L. Wäckers. 2003. Interactions between above- and belowground insect herbivores as mediated by the plant defense system. Oikos 101:555-562.

Bory, G., and D. Clair Maczulajtys. 1986. Nectar composition and role of the extrafloral nectar in Ailanthus glandulosa. Canadian Journal of Botany 64:247-253.

Daumann, E. 1932. Über postflorale Nektarabscheidung. Beihefte zum botanischen Centralblatt 49:720-734.

Engel, V., M. K. Fischer, F. L. Wäckers, and W. Völkl. 2001. Interactions between extrafloral nectaries, aphids and ants: are there competition effects between plants and homopteran sugar sources? Oecologia 129:577-584.

Ford, H. A., and N. Forde. 1976. Birds as possible pollinators of Acacia pycnantha. Australian Journal of Botany 24:793795.

Fryxell, P. A. 1979. Natural history of the cotton tribe. Texas A\&M University Press, College Station, Texas, USA.

Gracie, C. 1991. Observation of dual function of nectaries in Ruellia radicans (Nees) Lindau (Acanthaceae). Bulletin of the Torrey Botanical Society 118:188-190.

Haslam, E. 1986. Secondary metabolism: fact and fiction. Natural Product Reports 3:217-249.

Heil, M., T. Koch, A. Hilpert, B. Fiala, W. Boland, and K. E. Linsenmair. 2001. Extrafloral nectar production of the ant-associated plant, Macaranga tanarius, is an induced, indirect, defensive response elicited by jasmonic acid. Proceedings of the National Academy of Sciences (USA) 98: 1083-1088.

Inouye, D. W. 1983. The ecology of nectar robbing. Pages 153-173 in B. Bentley and T. Elias, editors. The biology of nectaries. Columbia University Press, New York, New York, USA.

Jervis, M. A., N. A. C. Kidd, and G. E. Heimpel. 1996. Parasitoid adult feeding behaviour and biocontrol-a review. Biocontrol News and Information 17:11N-26N.

Josens, R. B., W. M. Farina, and F. Roces. 1998. Nectar feeding by the ant Camponotus mus as a function of sucrose concentration. Journal of Insect Physiology 44:579-585.

Karban, R., and I. T. Baldwin. 1997. Induced responses to herbivory. University of Chicago Press, Chicago, Illinois, USA.

Keeler, K. H. 1981. Function of Mentzelia nuda (Loasaceae) postfloral nectaries in seed defense. American Journal of Botany 68:295-299.

Koptur, S. 1989. Is extrafloral nectar production an inducible defence? Pages 323-339 in J. Bock and Y. Linhart, editors. Evolutionary ecology of plants. Westview Press, Boulder, Colorado, USA.

Koptur, S. 1992. Extrafloral nectary-mediated interactions between insects and plants. Pages 81-129 in E. Bernays, editor. Insect-plant interactions. CRC Press, Boca Raton, Florida, USA.

Koptur, S., and J. H. Lawton. 1988. Interactions among vetches bearing extrafloral nectaries, their biotic protective agents, and herbivores. Ecology 69:278-283.

Kranz, J., H. Schmutterer, and W. Koch. 1977. Diseases, pests and weeds in tropical crops. Paul Parey, Berlin, Germany.

Martínez del Rio, C., J. E. Schondube, T. J. McWhorter, and L. G. Herrera. 2001. Intake responses in nectar-feeding birds: digestive and metabolic causes, osmoregulatory consequences, and coevolutionary effects. American Zoologist 41:902-915.

McGregor, S. E. 1976. Insect pollination of cultivated crop plants. U.S. Government Printing Office, Washington, D.C., USA.

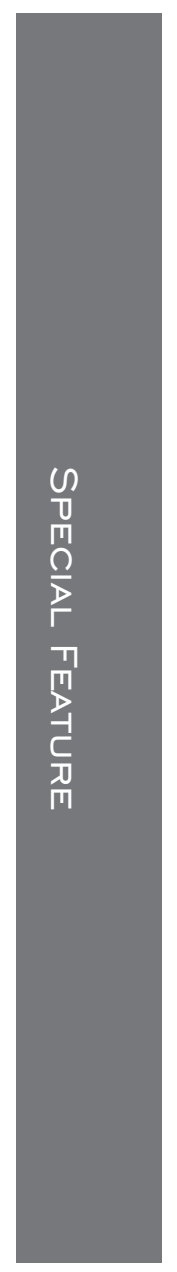


McKey, D. 1974. Adaptive patterns in alkaloid physiology. American Naturalist 108:305-320.

McKey, D. 1979. The distribution of secondary compounds within plants. Pages 56-133 in G. Rosenthal and D. Janzen, editors. Herbivores: their interaction with secondary plant metabolites. Academic Press, New York, New York, USA.

Ness, J. H. 2003. Catalpa bignonioides alters extrafloral nectar production after herbivory and attracts ant bodyguards. Oecologia 134:210-218.

Orians, C. M., J. Pomerleau, and R. Ricco. 2000. Vascular architecture generates fine scale variation in systemic induction of proteinase inhibitors in tomato. Journal of Chemical Ecology 26:471-485.

Porter, S. D. 1989. Effects of diet on the growth of laboratory fire ant colonies (Hymenoptera: Formicidae). Journal of the Kansas Entomological Society 62:288-291.

Raine, N. E., P. Willmer, and G. N. Stone. 2002. Spatial structuring and floral avoidance behavior prevent ant-pollinator conflict in a Mexican ant-acacia. Ecology 83:30863096.

Rhoades, D. F. 1979. Evolution of plant chemical defense against herbivores. Pages 4-54 in G. A. Rosenthal and D. H. Janzen, editors. Herbivores: their interaction with secondary plant metabolites. Academic Press, New York, New York, USA.

Rhyne, C. L. 1965. Inheritance of extrafloral nectaries in cotton. Advances and Frontiers in Plant Science 13:121135.

Rudgers, J. A. 2002. Evolutionary ecology of ant-wild cotton associations. Dissertation. University of California, Davis, California, USA.

Rudgers, J. A. 2003. Behavioral mechanisms underlie an antplant mutualism. Oecologia 135:51-59.

Sazima, I., S. Buzato, and M. Sazima. 1993. The bizarre inflorescence of Norantea brasiliensis (Marcgraviaceae) visits of hovering and perching birds. Botanica Acta 106: 507-513.

Tilman, D. 1978. Cherries, ants, and tent caterpillars: timing of nectar production in relation to susceptibility of caterpillars to ant predation. Ecology 59:686-692.
Tobin, J. E. 1994. Ants as primary consumers: diet and abundance in the Formicidae. Pages 279-307 in J. H. Hunt and C. A. Nalepa, editors. Nourishment and evolution in insect societies. Westview Press, Boulder, Colorado, USA.

Trelease, W. 1879. Nectar, what it is and some of its uses. U.S. Department of Agriculture Report on Cotton Insects 3:319-343.

Van Rijn, P. C. J., Y. M. Van Houten, and M. W. Sabelis. 2002. How plants benefit from providing food to predators even when it is also edible to herbivores. Ecology 83:26642679.

Wäckers, F. L. 2003. The effect of food supplements on parasitoid-host dynamics. Proceedings of the International Symposium on Biological Control of Arthropods (ISBCA) 1:226-231.

Wäckers, F. L., and A. Steppuhn. 2003. Characterizing nutritional state and food source use of parasitoids collected in fields with high and low nectar availability. IOBC WPRS (International Organization for Biological and Integrated Control of Noxious Animals and Plants-West Palearctic Regional Section) Bulletin 26:203-208.

Wäckers, F. L., D. Zuber, R. Wunderlin, and F. Keller. 2001. The effect of herbivory on temporal and spatial dynamics of extrafloral nectar production in cotton and castor. Annals of Botany 87:365-370.

Wagner, D., and A. Kay. 2002. Do extrafloral nectaries distract ants from visiting flowers? An experimental test of an overlooked hypothesis. Evolutionary Ecology Research 4:293-305.

Wullschleger, S. D., and D. M. Oosterhuis. 1990. Photosynthetic carbon production and use by developing cotton leaves and bolls. Crop Science 30:1259-1264.

Zangerl, A. R., and F. A. Bazzaz. 1992. Theory and pattern in plant defense allocation. Pages 363-392 in R. Fritz and E. L. Simms, editors. Plant resistance to herbivores and pathogens. University of Chicago Press, Chicago, Illinois, USA.

Zangerl, A. R., and C. E. Rutledge. 1996. The probability of attack and patterns of constitutive and induced defense: a test of optimal defense theory. American Naturalist 147: 599-604. 